\title{
STABILITY AND ISOMERISATION OF LYCOPENE IN OIL-BASED MODEL SYSTEM DURING ACCELERATED SHELF-LIFE TESTING
}

\author{
Dalia Urbonaviciene*, Ramune Bobinaite, Ceslovas Bobinas, Pranas Viskelis \\ Biochemistry and Technology Laboratory, Institute of Horticulture, Lithuanian Research Centre for Agriculture and Forestry, \\ Kaunas str., Babtai, Kaunas distr., Lithuania, e-mail:d.urbonaviciene@lsdi.lt
}

\begin{abstract}
Shelf-life prediction of a product could be assessed by measuring quality attributes through accelerated shelf-life testing (ASLT) under extreme conditions. The ASLT could be beneficial to specify the effects of different storage temperatures on quality properties of food products in some cases where the environmental conditions exceed the limits. The objective of this study was to evaluate the effect of temperature and light on lycopene stability in oil-based food model system during 100 days of storage. Extract of lycopene in oil-based model system was prepared from 'Tolstoi H' tomatoes and virgin rapeseed oil and poured into transparent vials. Samples were tested at $1 \pm 1{ }^{\circ} \mathrm{C}$ temperature in absence of light, ambient temperature at $20 \pm 1{ }^{\circ} \mathrm{C}$ in natural light, ambient temperature at $20 \pm 1^{\circ} \mathrm{C}$ in absence of light, at $40 \pm 1{ }^{\circ} \mathrm{C}$ temperature in absence of light and at $40 \pm 1{ }^{\circ} \mathrm{C}$ temperature in UV irradiation. Lycopene and its cis-isomers in oilbased model system and control were determined by high performance liquid chromatography (HPLC/DAD). The colour measurements of the samples were made using MiniScan XE Plus spectrophotometer. The addition of tomato extracts to vegetable oil might increase the level of lycopene in a human diet and enhance its bioavailability. The optimum storage conditions for lycopeneenriched oil were at $20^{\circ} \mathrm{C}$ in the dark. The temperature and light irradiation has a combined influence on the lycopene stability and isomerisation (from 17 to $100 \%$ changes from trans- to cis-lycopene isomers). ASLT is useful and practical tool for the stability monitoring of lycopene.
\end{abstract}

Keywords: lycopene, stability, isomerisation, accelerated shelf-life testing.

\section{Introduction}

Consumers increasingly demand products with high quality (taste, appearance, texture, flavour) whilst keeping their nutritional value. For this purpose, determining properties of food products during their shelf life is very important for the research and the food industry. The definition of self-life provides information regarding the time during which the product appropriately retains its quality (Ganje et al., 2016). This prediction could be performed by measuring quality attributes through accelerated shelf life testing (ASLT) under extreme conditions (Shao et al., 2015). However, the ASLT could be beneficial to specify the effects of different storage temperatures on quality properties of food products in some cases where the environmental conditions exceed the limits. The data in the literature generally agree that carotenoids is quite stable in fresh tomato matrices, but during thermal treatments, UV exposure or when carotenoids is dissolved in organic solvent, degradation and isomerisation can occur rapidly (Maiani et al., 2009). The kinetics of pigments degradation is complex in food products. Kinetics studies are capable of determines parameters such as reaction order and constant rates are required, being equally important to establish the impact on the food acceptability (Van Boekel, 2008).

Pedro and Ferreira (2006) used ASLT as an approach for determining the shelf-life of commercial concentrated tomato products and they reported zero and first order kinetic reactions for the quality factors of the product. The effects of thermal- and light-irradiation processing on lycopene stability in an oil-based food model system have not yet been completely investigated. The stability of lycopene during heating and illumination has been studied, but the results are controversial. Only a few studies was described the kinetics of cis-lycopene formation (Ax et al., 2003; Shi et al., 2000, Colle et al., 2010b).
The objective of this study was to evaluate the effect of temperature and light irradiation on lycopene stability in oil-based food model system during 100 days of storage.

\section{Materials and Methods \\ Materials}

The experiments were performed in the Laboratory of Biochemistry and Technology of the Institute of Horticulture, Lithuanian Research Centre for Agriculture and Forestry. Fresh tomato (Lycopersicon esculentum L.) of the hybrid 'Tolstoi H' (grown in the greenhouses of the Institute of Horticulture) and rapeseeds oil (Lithuania) were used.

The HPLC-grade solvents, including tetrahydrofuran, methanol, methyl-tert-butyl ether and ethyl acetate, were obtained from Sigma-Aldrich (Germany).

Sample preparation.

The lycopene rich oil-based food model systems were prepared using virgin rapeseed oil according to Urbonaviciene et al. (2015) with slight modification. The extract with lycopene (containing $25 \mathrm{mg} \cdot \mathrm{mL}^{-1}$ lycopene) was poured into 20 unit $2 \mathrm{~mL}$ transparent vials, and the extract was divided into five groups. Stability of lycopene in oil-based food model system was investigated during 100 days of storage period. Storage conditions were as follows:

1) at $1 \pm 1{ }^{\circ} \mathrm{C}$ temperature in dark $\left(1^{\circ} \mathrm{C}\right.$, dark $)$,

2) ambient temperature at $20 \pm 1{ }^{\circ} \mathrm{C}$ in natural light (day and night illumination was differ $(300 \pm 10$ Lux $))$ $\left(20{ }^{\circ} \mathrm{C}\right.$, light $)$,

3) ambient temperature at $20 \pm 1{ }^{\circ} \mathrm{C}$ in absence of light $\left(20^{\circ} \mathrm{C}\right.$, dark),

4) thermostatically controlled temperature at $40 \pm 1{ }^{\circ} \mathrm{C}$ in UV irradiation $(2500 \pm 100 \mathrm{Lux}))\left(40^{\circ} \mathrm{C}, \mathrm{UV}\right)$,

5) thermostatically controlled temperature at $40 \pm 1{ }^{\circ} \mathrm{C}$ in absence of light $\left(40^{\circ} \mathrm{C}\right.$, dark $)$. 
The samples were stored in hermetically sealed containers. The control sample in our study was lycopene in oil-based food system on day zero (0). The control sample and all lycopene oil-based food model samples were prepared for HPLC analysis after storage.

Lycopene extraction for HPLC

The samples $(1 \mathrm{~mL})$ was extracted repeatedly with tetrahydrofuran and diluted until $25 \mathrm{~mL}$ and the total lycopene content and cis-lycopene isomers was analysed using HPLC.

HPLC analysis of lycopene and its isomers

The content of total lycopene and lycopene isomers was analysed by HPLC with diode array detection according modified version of the different methods and systems described by Heymann et al. (2013), MelendesMartines et al. (2013), Urbonaviciene et al. (2015). To quantify lycopene in the extract samples, a calibration curve was generated using an authentic all-translycopene standard. Levels of cis-lycopene isomers are given in all-trans-lycopene equivalents.

\section{Colour measurements}

The colour was measured by a spectrophotometer MiniScan XE Plus (Hunter Associates Laboratory Inc., USA). Colour measurements were carried out using the standard CIE L*, a*, b* coordinates (McGuire, 1992).

Kinetic data. The degradation rate constant of the total concentration of lycopene (all-trans- and cis-isomers forms) were calculated on lycopene stability in oil-based food model system using the following formula:

$$
k=-\operatorname{Ln}\left(C_{A} / C_{A 0}\right) / t
$$

where $C_{A}$ is the total amount of lycopene after storage; $C_{A O}$ is the initial amount of lycopene; $t$ is storage time.

\section{Statistical analysis}

The analysis were triplicated for each sample and mean values are presented. Differences at $\mathrm{p}<0.05$ were considered to be significant. All statistical analysis was performed using Statistica 8.0 (StatSoft, Czech Republic) and Excel 2007 (Microsoft Corporation).

\section{Results and Discussion}

The effect of storage conditions (temperature from +1 to $+40^{\circ} \mathrm{C}$ ) and different light irradiation (300-2500 Lux) on lycopene stability and possible isomerisation in oil-based food model system was investigated. The total lycopene and cis-lycopene isomers concentration were observed.

Figure 1 shows a change of the total lycopene $\left(\mu \mathrm{gL}^{-1}\right)$ during 100 days of storage. The storage conditions affect stability of lycopene in oil-based food model system. The lycopene content decreased significantly $(\mathrm{p}<0.05)$ at $40{ }^{\circ} \mathrm{C}$ in UV storage conditions, to compare with other treatments. The data of our study shows that the slowest lycopene degradation was in samples stored at 1 and $20^{\circ} \mathrm{C}$ temperatures in absence of light. Also the lycopene degradation rate was not significantly different to compare samples stored at $20^{\circ} \mathrm{C}$ in light (average value of $300 \mathrm{Lux}$ ) and at $40^{\circ} \mathrm{C}$ in dark (Figure 1) storage conditions. It could be explained that temperature and light irradiation have a combined impact to biologically active substances. A significant interaction between temperature and light irradiation was detected for lycopene degradation in accelerated shelf life storage conditions.

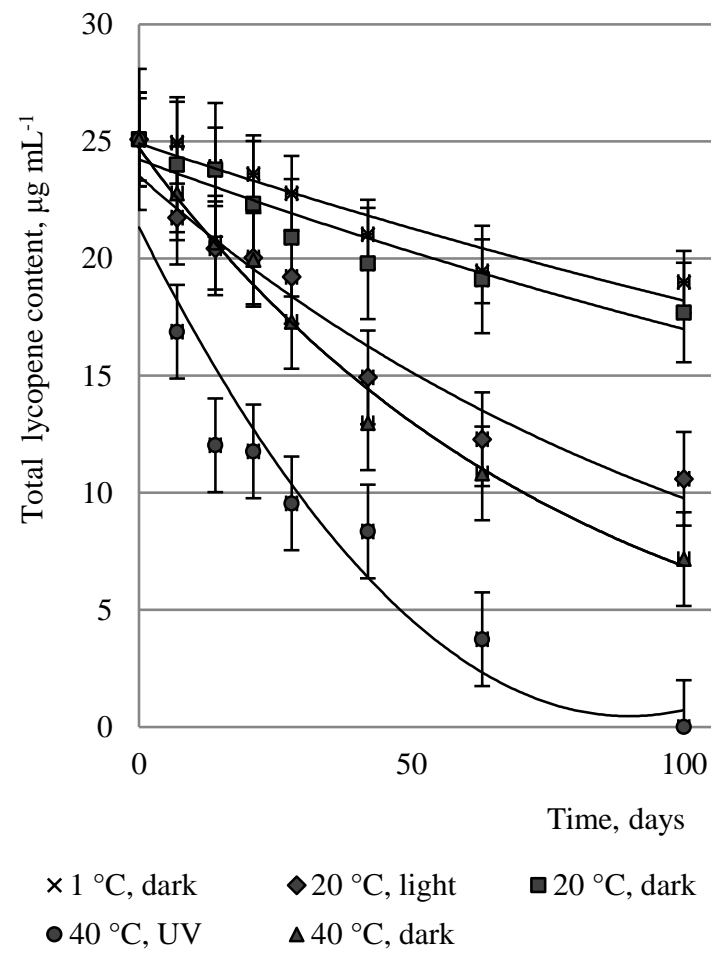

Figure 1. Degradation of total lycopene during the storage at various conditions

The degradation rate constants $(k)$ of the total concentration of lycopene were calculated. The lowest degradation of total lycopene was found at 1 and $20{ }^{\circ} \mathrm{C}$ in dark storage conditions $(\mathrm{k}=-0.002$ and $\mathrm{k}=-0.004$, respectively). The degradation rate constants values were similar to compare samples stored at $20^{\circ} \mathrm{C}$ in light $(-0.010)$ and at $40{ }^{\circ} \mathrm{C}$ in dark (-0.008). The degradation of lycopene in $40{ }^{\circ} \mathrm{C}$ UV sample was the most significant $(\mathrm{k}=-0.024)$. The decreasing amount of total lycopene may have been due to isomerisation, resulting from additional energy (temperature and / or light) input, which led to unstable, energy-rich situations (Shi, Le Maguer, 2000).

In nature, carotenoids, also lycopene, mostly exist in all-trans-isomers form. Thus, red tomatoes typically contain 94-96\% all-trans-lycopene. The double bonds of the carotenoids molecules can undergo isomerization from trans- to mono or poly-cis-isomers under the influence of heat, light, oxygen or certain chemical reactions in extracts and in food products from tomato. The changes of the total cis-isomers concentration during 100 days of storage are shown in Table 1 . The concentration of cis-lycopene increased in all treatments $\left(1{ }^{\circ} \mathrm{C}\right.$ at dark; $20{ }^{\circ} \mathrm{C}$ at dark; $20{ }^{\circ} \mathrm{C}$ at light and $40{ }^{\circ} \mathrm{C}$ at dark) in except for $40^{\circ} \mathrm{C}$ at UV irradiation after 100 days of storage. The concentration of cis-lycopene isomers increased until $45.8 \%$ after 42 day and decreased until $0 \%$ after 100 days in samples stored at $40{ }^{\circ} \mathrm{C}$ in UV irradiation. 
The changes of cis-lycopene isomers in samples stored at different conditions

\begin{tabular}{|c|c|c|c|c|c|c|c|c|c|}
\hline \multirow{2}{*}{$\begin{array}{c}\text { Sample } \\
\text { name }\end{array}$} & \multirow{2}{*}{$\begin{array}{c}\text { Time } \\
\text { (days) }\end{array}$} & \multicolumn{8}{|c|}{ Cis-lycopene isomers concentration, $\%$} \\
\hline & & $\mathbf{0}$ & 7 & 14 & 21 & 28 & 42 & 63 & 100 \\
\hline $1^{\circ} \mathrm{C}$, dark & & 0.00 & $3.3 \pm 0.08$ & $3.64 \pm 0.11$ & $4.46 \pm 0.12$ & $4.87 \pm 0.09$ & $6.50 \pm 0.16$ & $10.25 \pm 0.11$ & $10.77 \pm 0.22$ \\
\hline $20^{\circ} \mathrm{C}$, dark & & 0.00 & $6.1 \pm 0.20$ & $11.45 \pm 0.23$ & $15.31 \pm 0.09$ & $18.57 \pm 0.33$ & $23.61 \pm 0.22$ & $26.35 \pm 0.31$ & $28.69 \pm 0.14$ \\
\hline $20^{\circ} \mathrm{C}$, light & & 0.00 & $8.8 \pm 0.21$ & $12.44 \pm 0.17$ & $15.90 \pm 0.17$ & $16.81 \pm 0.15$ & $22.20 \pm 0.41$ & $29.50 \pm 0.36$ & $35.34 \pm 0.32$ \\
\hline $40^{\circ} \mathrm{C}, \mathrm{UV}$ & & 0.00 & $20.6 \pm 0.41$ & $31.73 \pm 0.24$ & $39.25 \pm 0.32$ & $41.54 \pm 0.71$ & $45.81 \pm 0.38$ & $34.31 \pm 0.30$ & 0.00 \\
\hline $40^{\circ} \mathrm{C}$, dark & & 0.00 & $25.54 \pm 0.30$ & $30.38 \pm 0.19$ & $32.86 \pm 0.24$ & $33.18 \pm 0.46$ & $34.32 \pm 0.27$ & $36.80 \pm 0.42$ & $37.09 \pm 0.44$ \\
\hline
\end{tabular}

The cis-isomers concentration increase was greater about $18 \%$ to compare the samples stored at $1{ }^{\circ} \mathrm{C}$ in dark and at $20^{\circ} \mathrm{C}$ in dark about $25 \%$ to compare the samples stored at $1{ }^{\circ} \mathrm{C}$ in dark and at $20^{\circ} \mathrm{C}$ in light after 100 days of storage. The data in the literature summarized that isomerisation from trans- to cis-carotenoids isomers could be a result of the overlapping of the methyl group of a carbon atom adjacent to a double bond and the hydrogen (Mercadante, 2007).

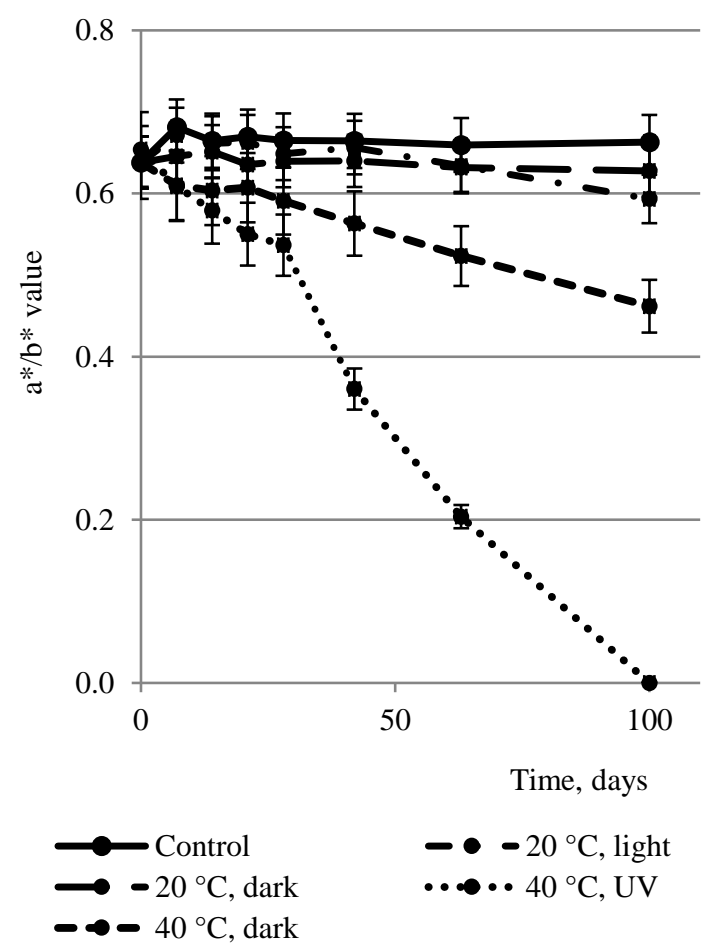

Figure 2. Change of samples colour expressed as $a * / b * d u r i n g$ the storage

Effect of colour change of lycopene oil-based food model system was investigated to compare the ratio $\mathrm{a}^{*}$ and $b^{*}$ change. The ratio of $a^{*}$ and $b^{*}$, indicate the change of redness, are shown in Figure 2. The $a^{*} / b^{*}$ value of the control was 0.64 and was not significant differences in samples stored at $1{ }^{\circ} \mathrm{C}$ in dark, at $20^{\circ} \mathrm{C}$ in dark and at $20^{\circ} \mathrm{C}$ in light $(0.63,0.62$ and $0.59(\mathrm{p} \geq 0.05)$, respectively after 100 days of storage. The $\mathrm{a}^{*} / \mathrm{b}^{*}$ value of the samples stored at $40{ }^{\circ} \mathrm{C}$ in dark and at $40{ }^{\circ} \mathrm{C}$ in dark were significantly different to compare with other storage conditions. The $\mathrm{a}^{*} / \mathrm{b}^{*}$ value was decreased to
0.46 of the samples stored at $40{ }^{\circ} \mathrm{C}$ in dark. The $\mathrm{a}^{*} / \mathrm{b}^{*}$ value of the sample stored at $40^{\circ} \mathrm{C}$ in UV decreased until 0.2 after 63 days and 0.0 after 100 days of storage. The results of a low $a^{*} / b^{*}$ value represented the colour change from yellow-red to brown colour due to the breakdown of lycopene (Shi, Le Maguer, 2000; Krebbers et al., 2003). The $a^{*} / b^{*}$ values of samples stored at low temperatures in light were significantly greater to compare samples stored at higher temperatures and especially samples irradiated with UV (Figure 2).

\section{Conclusions}

The optimum storage conditions for lycopene in oil based food model system were at $1{ }^{\circ} \mathrm{C}$ temperature in the dark. The temperature and light irradiation has a combined influence on the lycopene stability and isomerisation (from 17 to $100 \%$ changes from trans- to cis-lycopene isomers). The ratio of $\mathrm{a}^{*}$ and $\mathrm{b}^{*}$ colour coordinates indicates the changed as a function of storage illumination. ASLT is useful and practical tool for the stability monitoring of lycopene.

\section{Acknowledgment}

This work was supported by the grant from the Research Council of Lithuania, No. MIP-62/2015.

\section{References}

1. Ax K., Mayer-Miebach E., Link B., Schuchmann H., Schubert H. (2003) Stability of lycopene in oil-in-water Emulsions. Engineering in life sciences, Vol. 3 (4), p. 199-201.

2. Chen J., Shi J., Xue S. J., Ma Y. (2009) Comparison of lycopene stability in water-and oil-based food model systems under thermal-and light-irradiation treatments. LWT-Food Science and Technology, Vol. 42 (3), p. 740-747.

3. Colle I., Van Buggenhout S., Van Loey A., Hendrickx M. (2010) High pressure homogenization followed by thermal processing of tomato pulp: Influence on microstructure and lycopene in vitro bioaccessibility. Food Research International, Vol. 43 (8), p. 2193-2200.

4. Ganje M., Jafari S. M., Dusti A., Dehnad D., Amanjani M., Ghanbari V. (2016) Modeling quality changes in tomato paste containing microencapsulated olive leaf extract by accelerated shelf life testing. Food and Bioproducts Processing, Vol. 97, p. 12-19. 
5. Heymann T., Raeke J., Glomb M. A. (2013) Photoinduced isomerization of lycopene and application to tomato cultivation. Journal of Agricultural and Food Chemistry, Vol. 61 (46), p. 11133-11139.

6. Krebbers B., Matser A. M., Hoogerwerf S. W., Moezelaar R., Tomassen M. M., van den Berg R. W. (2003) Combined high-pressure and thermal treatments for processing of tomato puree: evaluation of microbial inactivation and quality parameters. Innovative Food Science \& Emerging Technologies, Vol. 4 (4), p. 377-385.

7. Maiani G., Periago Castón M. J., Catasta G., Toti E., Cambrodón I. G., Bysted A., Granado-Lorencio F., Olmedilla-Alonso B., Knuthsen P., Valoti M., Böhm, V., Mayer-Miebach E., Behsnilian D., Schlemmer U. (2009) Carotenoids: actual knowledge on food sources, intakes, stability and bioavailability and their protective role in humans. Molecular Nutrition \& Food Research, Vol. 53 (S2), p. 194-218.

8. McGuire R. G. (1992) Reporting of objective color measurements. Hort Science, Vol. 27 (12), p. 1254-1255.

9. Melendez-Martinez A. J., Stinco C. M., Liu C., Wang X. D. (2013) A simple HPLC method for the comprehensive analysis of cis/trans (Z/E) geometrical isomers of carotenoids for nutritional studies. Food Chemistry, Vol. 138 (2), p. 1341-1350.

10. Mercadante A.Z. (2007) Analysis of carotenoids, In Food colorants: chemical and functional properties. Wasington: CRC Press, 447-478 p.

11. Pedro A. M., Ferreira M. (2006) Multivariate accelerated shelf-life testing: a novel approach for determining the shelf-life of foods. Journal of Chemometrics, Vol. 20 (1-2), p. 76-83.

12. Shao P., Liu Q., Fang Z., Sun P. (2015) Chemical composition, thermal stability and antioxidant properties of tea seed oils obtained by different extraction methods: Supercritical fluid extraction yields the best oil quality. European Journal of Lipid Science and Technology, Vol. 117 (3), p. 355-365.

13. Shi J., Maguer M. Le. (2000) Lycopene in tomatoes: chemical and physical properties affected by food processing. Critical Reviews in Food science and nutrition, Vol. 40 (1), p. 1-42.

14. Shi J., Maguer M., Bryan M., Kakuda Y. (2003) Kinetics of lycopene degradation in tomato puree by heat and light irradiation. Journal of Food Process Engineering, Vol. 25 (6), p. 485-498.

15. Urbonaviciene D., Viskelis P., Viskelis J., Bobinas C. (2015) Stability of tomato lycopene under thermal-and light-irradiation treatments in an oil-based model system. Žemdirbyste (Agriculture), Vol. 102 (2), p. 185-192.

16. Van Boekel M. A. (2008) Kinetic modelling of food quality: A critical review. Comprehensive Reviews in Food Science and Food Safety, Vol. 7 (1), p. 144-158.

17. Zhang L., Zhang H., Ndeurumi K. H., Parkin K. L., Venuste M. (2012) Thermally-induced geometrical isomerisation of lycopene and its potential influence on functional activity. Food Chemistry, Vol. 132 (4), p. 2112-2117. 